\title{
ESTUDOS GEOFÍSICOS DE UMA ÁREA EXPERIMENTAL, NA REGIÃO SEMI-ÁRIDA DO NORDESTE, PARA ARMAZENAMENTO SUBTERRÂNEO DE ÁGUA
}

\author{
OLIVAR A. L. DE LIMA* e CARLOS A. DIAS*
}

\begin{abstract}
A sandstone unit of the Sergi Formation in the region of Cocorobó - Bahia was selected as an experimental area for an appraisal of the feasibility of artificial injection of water in sedimentary underground reservoirs of the semiarid region of the Brasilian Northeast. Geological mapping of the region showed that these sandstones occur intercalated with argillaceous lithologies in a block-faulted structure, a quite common framework in that region. Some fault zones are impervious due to silicification along the planes of rupture. The threedimensional geometrical configuration of the formation were delineated using AFMAG (audio-frequency magnetic), electrical and seismic refraction methods. The AFMAG measurements yielded a very good delineation of the fault systems of the area. Electrical soundings and seismic profilings defined the geometry of the reservoir, and gave qualitative informations about its boundaries and the hydrological properties of the sandstones at depth. Direct observations, in a well drilled through the formation, showed that the reservoir is undersatured under the conditions prevailing in that semiarid environment.
\end{abstract}

\begin{abstract}
INTRODUÇÃO Com base em estudos geológicos foi selecionada uma área experimental na bacia sedimentar de Tucano, na região de Cocorobó, Município de Euchides da Cunha - Bahia, visando a sua utilização em testes de armazenamento artificial subterrâneo de água (Lima, 1979).

Neste trabalho, são apresentados os resultados obtidos na determinação de elementos estruturais e da configuração tridimensional de um corpo de areniţo da Formação Sergi, escolhido para ser utilizado como reservatório natural para o armazenamento de água. Neste estudo, foi realizada, pela primeira vez no País, a utilização de método eletromagnético (AFMAG) no mapeamento de falhas em ambientes sedimentares. Foram ain$\mathrm{da}$, combinados os métodos elétricos e sísmicos com dados de perfuração, na determinação dos parâmetros geométricos, resolvendo assim problemas de ambigüidade de interpretação. A diversificação dos métodos geofísicos utilizados permitiu também inferir conclusões a respeito das características petrofísicas macroscópicas do corpo de arenito. As características hidráulicas regionais do reservatório constituíram assunto de um outro artigo pelos autores (Lima e Dias, 1979).

Os estudos geofísicos anteriormente realizados sobre regiões do Nordeste brasileiro (Barros e Feitosa, 1967; Rijo et al., 1977) empregaram somente o método de eletrorresistividade para determinação da espessura e configuração geométrica, em escala regional, de aquíferos de estruturas relativamente simples, contando com dados de alguns perfis de poços para controle da interpretação.
\end{abstract}

SITUAÇÃO GEOLÓGICA A região estudada (Fig. 1) tem uma área de aproximadamente $45 \mathrm{~km}^{2}$ e situa-se na borda ocidental da Bacia de Tucano. Essa bacia constitui um graben encravado no escudo brasileiro e preenchido de sedimentos jurássicos a terciários.

O substrato precambriano é constituído de ardósias, filitos e leitos de metacalcário escuro da Série Canudos (Humphrey e Allard, 1969), sobre o qual repousam discordantemente as rochas sedimentares do Supergrupo Bahia (Viana et al., 1971).

O Supergrupo Bahia compreende uma seqüência de folhelhos e arenitos inter-estratificados que constituem as formações geológicas indicadas na Fig. 1. Nesse supergrupo, a Formação Sergi é a unidade litológica mais favorável ao armazenamento de água. A mesma é constituída de arenitos de granulação fina a média, pouco cimentados, com niveis conglomeráticos na seção superior. Esses arenitos estão intercalados estratigraficamente em litologias finas, dominantemente argilosas, que correspondem respectivamente na base e no topo às Formações Aliança e Itaparica (Fig. 1).

As principais feições estruturais da região são os falhamentos de gravidade e os sistemas de ruturas a eles associados, que produziram um conjunto de blocos falhados. Algumas das zonas de falhas, que limitam lateralmente a Formação Sergi, estão associadas com intensa silicificação e catáclase, podendo ser facilmente reconhecidas no campo, ou em fotos aéreas, pela presença de estreitas cristas silicificadas alinhadas por grande extensão. Todavia muitas outras, especialmente aquelas que intersectam litologias argilosas, foram mapeadas por inferência, conforme discutido mais adiante.

O mergulho geral das camadas é para SE, com valores inferiores a $15^{\circ}$. Essa atitude pode ser ligeiramente modificada nas proximidades de falhas, às vezes acentuando seus ângulos de mergulho até $30^{\circ}$.

\footnotetext{
* Programa de Pesquisa e Pós-graduação em Geofísica - Instituto de Oeociências da UFBa, R. Caetano Moura, 123, Salvador Bahia - Brasil.
} 


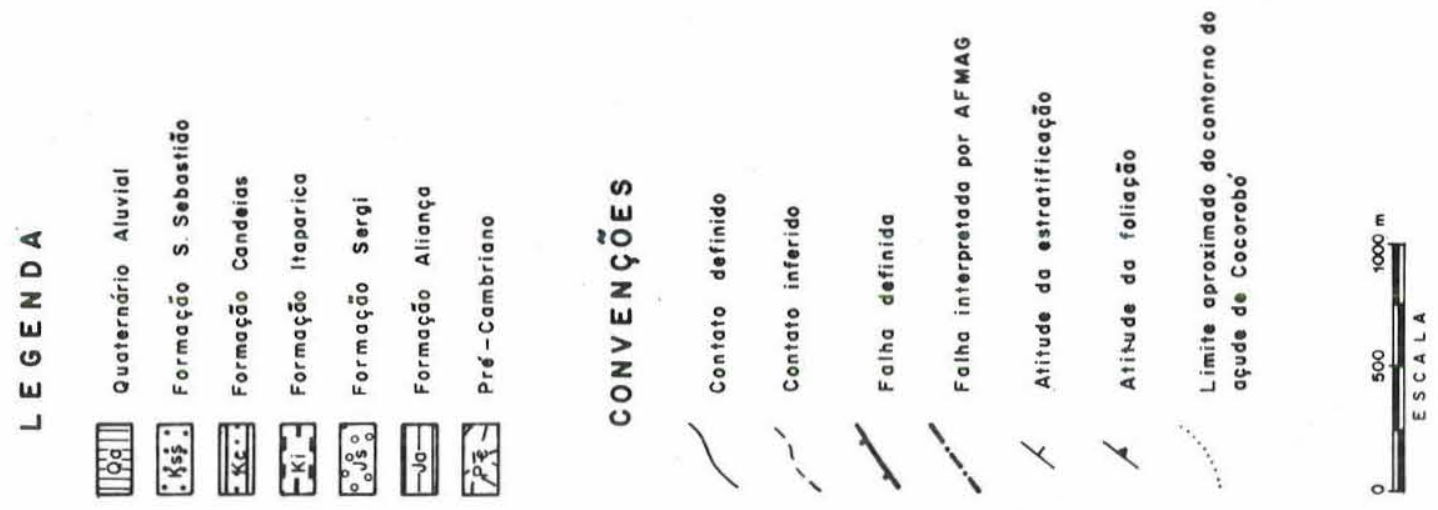

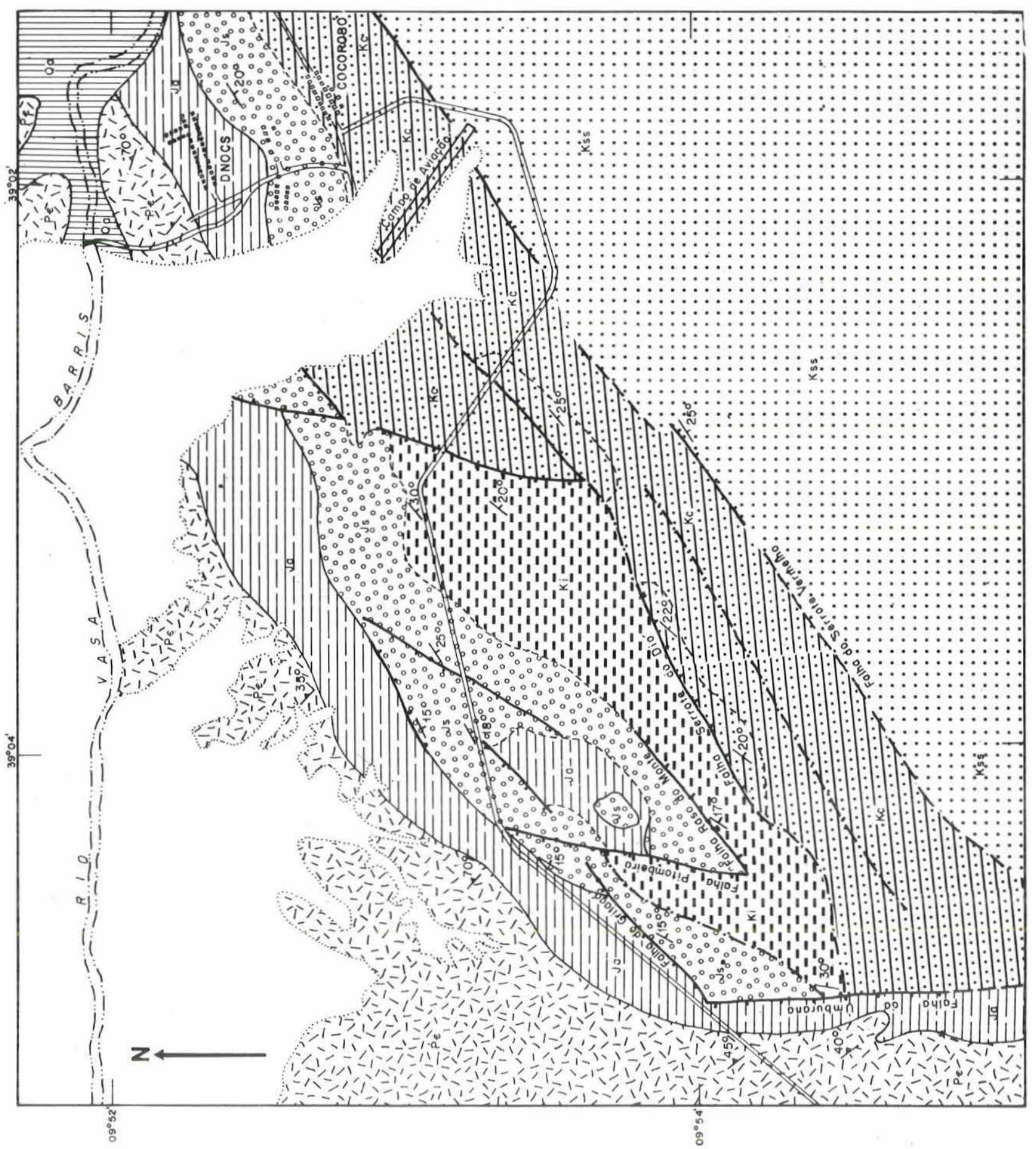


INVESTIGAÇÃO GEOFISICA Mapeamento dos sistemas de falhas Para confirmar a continuidade lateral inferida de algumas das falhas, assim como investigar a presença de outras que não são aflorantes, foi empregado o método eletromagnético AFMAG. Esse método utiliza os campos magnéticos naturais na faixa de áudio-freqüências, produzidos principalmente por descargas elétricas na baixa atmosfera (Ward et al., 1966).

Durante o levantamento, foram medidos o azimute e o ângulo de mergulho do eixo principal do elipsóide de polarização do campo natural ao longo de linhas transversais à estrutura geológica. Foram levantadas seis linhas aproximadamente perpendiculares à direção das maiores falhas, com intervalo de $50 \mathrm{~m}$ entre as estações de medida. $\mathrm{O}$ equipamento utilizado nesse levantamento, Mod. A-652 da McPhar Geophysics, opera nas freqüências de 140 e $470 \mathrm{~Hz}$.

$\mathrm{Na}$ interpretação qualitativa das anomalias de AFMAG, foi utilizado o esquema proposto por Sampaio (1978), para um modelo de semi-espaço contendo planos verticais de descontinuidade da resistividade, utilizando ângulos de inclinação do eixo maior da elipse (do campo natural), observados num plano perpendicular ao plano de descontinuidade.

No nosso caso, a direção do eixo principal do elipsóide de polarização (do campo natural) não necessariamente coincide com a linha adotada para o levantamento, mas flutua em torno desta direção, com pequena dispersão. Por exemplo, para as 68 leituras registradas ao longo da linha C-1 (Fig. 2), o valor médio do azimute foi praticamente coincidente com a direção da linha de picada $\mathrm{N} 336^{\circ}$, com desvio-padrão igual a $14,9^{\circ}$. Nas demais linhas, repete-se aproximadamente o mesmo padrão. Desse modo, justifica-se o emprego dos resultados de Sampaio (1978), sendo as seguintes regras utilizadas na interpretação dos perfis:

a) a posição de uma descontinuidade de resistividade é definida por um ponto de cúspide no perfil de ângulo de mergulho. Os valores desses ângulos decaem a zero, mais rapidamente sobre o lado condutivo do que sobre o lado resistivo;

b) a amplitude dos picos nos perfis aumenta com o contraste de resistividade das rochas postas em contato;

c) corpos condutores ou resistivos em forma de diques têm seus limites laterais definidos por pontos de cúspides e são caracterizados por inversão dos sinais de ângulo de mergulho, correspondendo o zero (ponto de cruzamento) ao centro do corpo;

d) a amplitude dos picos associados a corpos em forma de dique diminui, para um mesmo contraste de resistividade, com a espessura do corpo;

e) nos dados de campo, os pontos de cúspides nas curvas de ângulo de mergulho podem ser aproximados pelos valores máximos ou mínimos das curvas.

As curvas de ângulo de mergulho do campo natural para as duas freqüências utilizadas, lançadas na forma de perfis sobre as informações da geologia de superfície, estão mostradas na Fig. 2, onde convencionamos como positivos os ângulos de mergulho com sentido sul.

A Falha do Serrote Vermelho (Fig. 2), que havia sido inferida em sua maior extensão durante o mapea- mento geológico, vem claramente definida em todas as linhas levantadas. A posição do pico positivo coincide aproximadamente com a posição inferida da falha, nos casos em que foi possivel essa comparação. A existência nos perfis de um ponto de inversão do sinal e de um pico negativo à esquerda dessa falha define uma faixa lateral condutora ao norte, cujo limite a NW corresponde à existência de uma falha não identificada pelo mapeamento geológico.

A Falha Serrote do Dió (Fig. 2), bem evidente em superfície, aparece registrada por pequenos picos positivos em todos os perfis. Essa redução nas amplitudes dos picos reflete um menor contraste de condutividade das rochas postas em contato ao longo da falha. Os pontos de inversão do sinal, um pouco ao norte da falha, evidenciam a adjacência de um corpo condutor que, de acordo com o mapa geológico da Fig. 1, corresponde aos folhelhos da Formação Itaparica.

A Falha Raso no Monte (Fig. 2) aparece registrada ao longo da linha $\mathrm{C}-2$, possuindo prolongamento para oeste além da Falha Pitombeira, conforme definido pelo pico negativo dos perfis ao longo da linha C-5.

As Falhas Pitombeira, do Gritagó e da Umburana são registradas pelo método AFMAG, sempre que cruzam com os perfis C-4, C-5 e C-6. A Falha do Gritagó, nas linhas $\mathrm{C}-4$ e $\mathrm{C}-5$, foi interpretada como indicativa da presença de um dique resistivo de $200 \mathrm{~m}$ de largura, fato que confirma a extensão lateral do processo de silicificação verificado em superfície, e sugere o seu prolongamento em profundidade. A linha C-6 cruza em ânguko baixo a Falha da Umburana, também silicificada, o que dificulta a interpretação geofísica, mas ainda assim é possivel notar, na curva da freqüência alta, a presença de um estreito corpo resistivo.

Os perfis das linhas C-4 e C-5, além de registrar as Falhas do Gritagó e da Pitombeira, mostram picos (de pequena amplitude) sugerindo a existência, sob a cobertura de solo arenoso, do contato entre a Formação Sergi e a Formação Itaparica, claramente identificado nos estudos de resistividade e de sísmica de refração, descritos adiante neste trabalho.

Determinação geométrica da estrutura subterrânea Para determinar a configuração geométrica do reservatório em sub-superfície, foram utilizados os métodos de eletrorresistividade e de sísmica de refração. Foram executadas sondagens elétricas para verificar a continuidade lateral do arenito, mapear suas superfícies basal e de topo, bem como verificar a presença de água no reservatório. Perfis sísmicos de refração, em combinação com os dados elétricos, foram obtidos para melhor determinação dos contornos do arenito e fornecer outras informações adicionais de utilidade na avaliação da uniformidade da sua porosidade.

Eletrorresistividade Foram efetuadas 20 sondagens elétricas em torno de pontos escolhidos da área (Fig. 3), empregando o arranjo de Wenner. Usou-se o equipamento de fabricação da ABEM Mod. 6.310, que opera a uma freqüência nominal de $4 \mathrm{~Hz}$.

Os dados de campo foram obtidos adotando o procedimento conhecido na literatura por arranjo tripotencial (Carpenter e Habberjam, 1956). Esse procedimento 


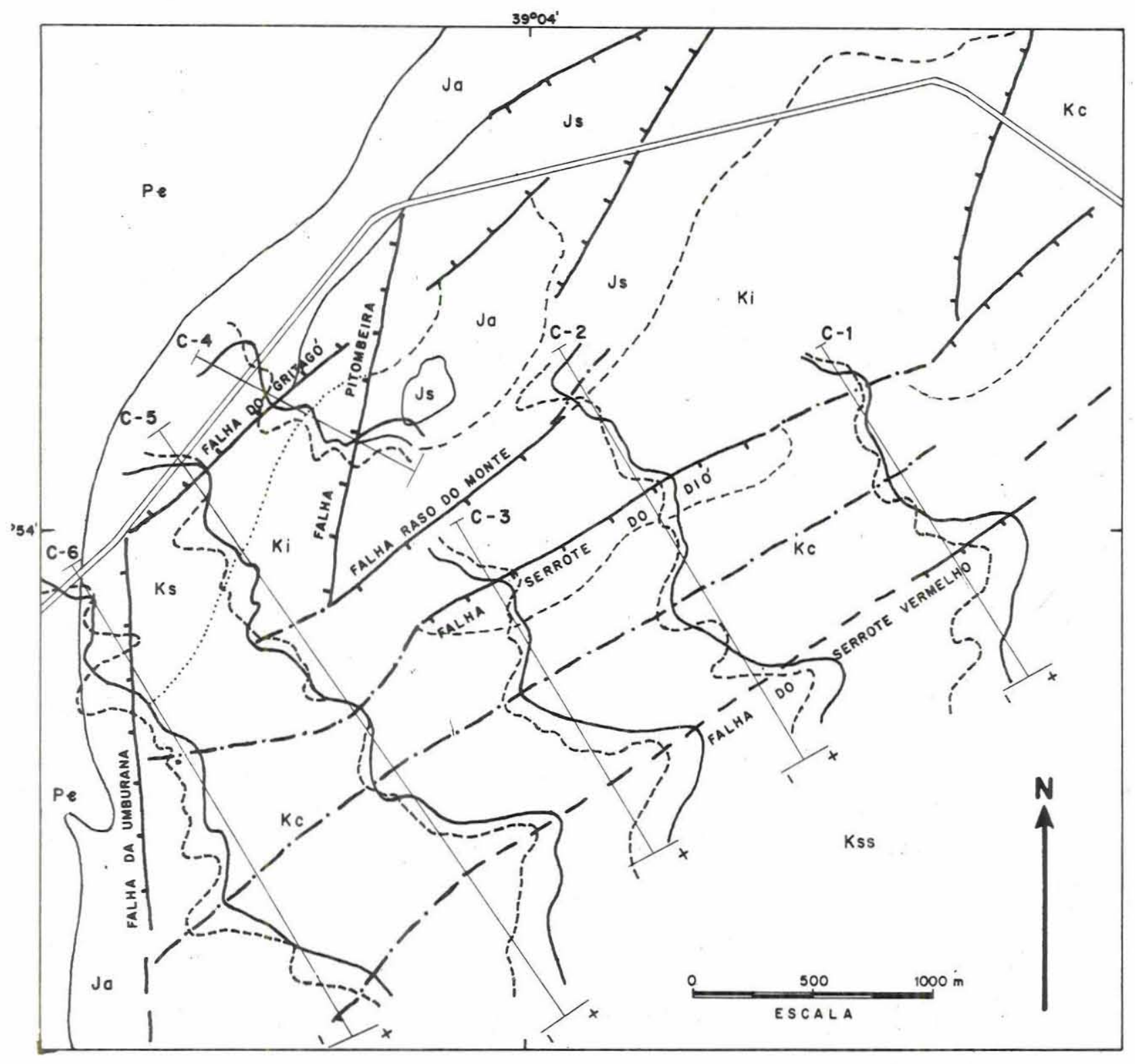

\section{LEGENDA}

Kss Formação S. Sebastiõo

Kc Formação Candeias

$\mathrm{Ki}$ Formação Itaparica

Js Formação Sergi

Ja Formaçăo Aliança

Pe Pré-Cambriano

.- Contato geológico gradacional Contato mapeado com base nos diversos dados geofísicos

Falha mapeada por fotointerpretação geológica

Falha interpretada por AFMAG

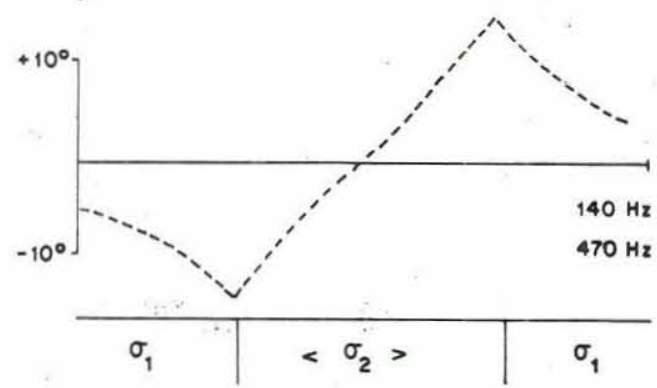




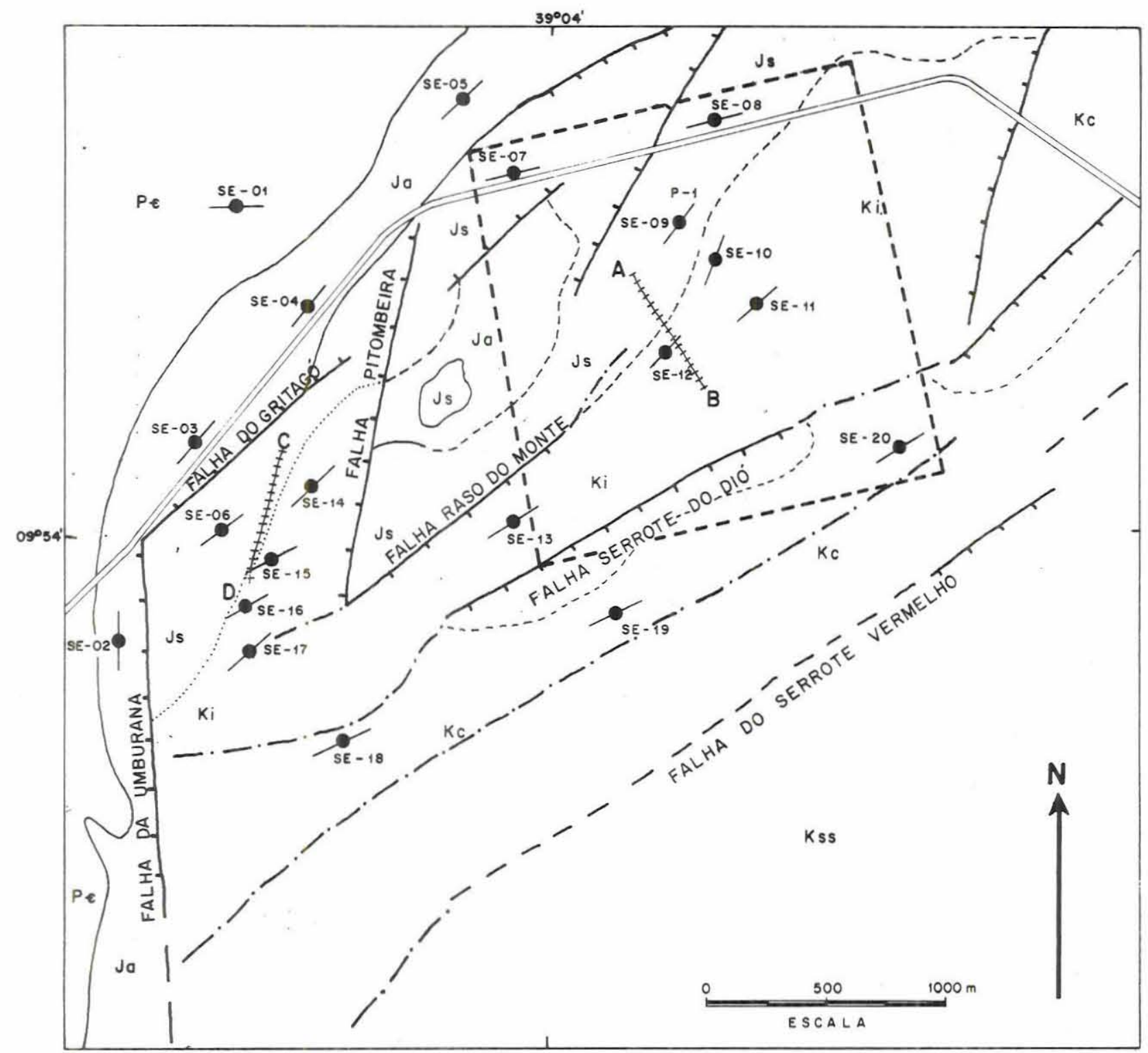

\section{LEGENDA}

Kss Formação S. Sebastião

Kc Formação Condeias

Ki Formação Itaparica

Is Formação Sergi

Ja Formação Aliança

Pe Pré-Cambriano

...' Contato geológico gradacional

Contato mapeado com base nos diversos dodos geofísicos

Falha mapeada por fotointepretacãa geológica

. Falha interpretada por AFMAG

Linho de refração sismica

- Centro de sondagem elétrica e direção de expansão 
serve para eliminar as contribuições espúrias das medidas, tal como o efeito de correntes telúricas, e ainda fornecer os elementos para uso da técnica de redução dos efeitos de variações laterais de resisitividade, proposta por Habberjam e Watkins (1967), para interpretação de sondagens elétricas de regiões estratificadas complexas, utilizando em caráter local o modelo de camadas horizontais.

$\mathrm{Na}$ interpretação das curvas de resistividade aparente, obtidas após redução de efeitos laterais segundo a técnica referida, foi adotado o procedimento de superposição completa das curvas, fazendo uso de um com- putador IBM-360 para gerar as curvas teóricas. Foi utilizado para isso o método numérico proposto por Mooney et al. (1966). A unicidade da solução foi implementada através da informação sobre as espessuras das camadas abaixo do ponto SE-09, por meio de perfuração, e ainda dados complementares fornecidos pela sísmica de refração. Foi ainda de utilidade para isso a correlação entre sondagens elétricas realizadas em pontos vizinhos.

A curva da sondagem elétrica SE-01 (Fig. 4), executada na área de exposição do embasamento pré-cambriano, indica que, abaixo de $25 \mathrm{~m}$ de profundidade, a resistividade dos filitos é praticamente infinita. So-

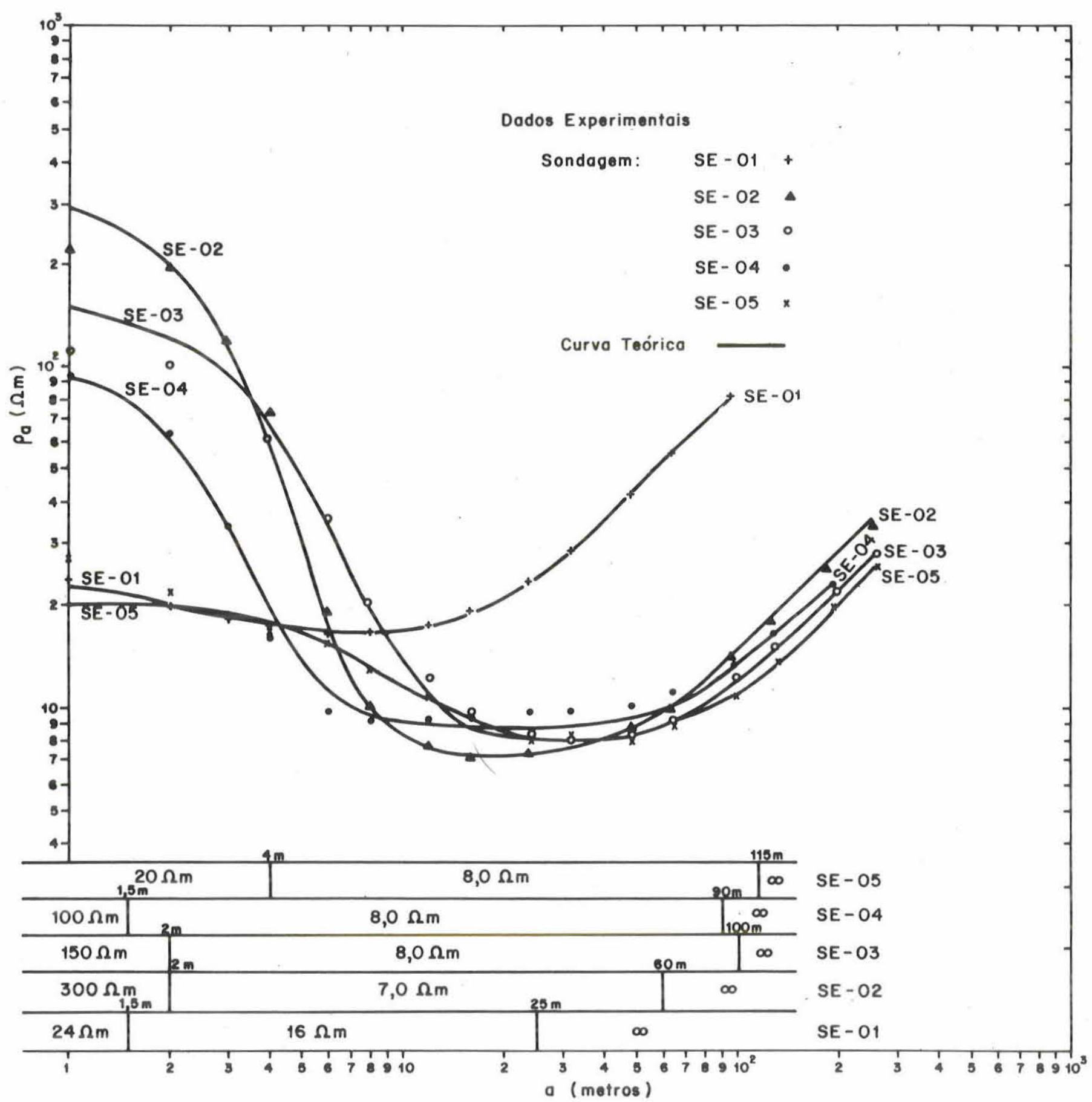

Figura 4 - Curvas de sondagens elétricas obtidas sobre o embasamento e sobre a Formação Aliança 
breposta a essa zona ocorre uma camada intermediária, de resistividade igual a $16 \Omega \mathrm{m}$, que representa a zona de clivagens e fraturas abertas, preenchidas com água. A camada superior, de $1,5 \mathrm{~m}$ de espéssura e $24 \Omega \mathrm{m}$ de resistividade, corresponde à zona de alteração superficial do filito, formada por cascalheira superficial.

Das sondagens executadas sobre a Formação Aliança, quatro são mostradas na Fig. 4, SE-02 a SE-05, todas indicando uma -seqüência resistiva-condutiva-resistiva. Considerando o conjunto dessas curvas, verifica-se que a primeira camada de resistividade, entre $20 \mathrm{e}$ $300 \Omega \mathrm{m}$, representa o solo superficial de composição e conteúdo de água variáveis. Os mínimos achatados das curvas de sondagem permitem a determinação segura da resistividade do espesso pacote de folhelhos, que corresponde à segunda camada, com resistividade de 7 a $8 \Omega \mathrm{m}$. Para espaçamentos superiores a $60 \mathrm{~m}$, as curvas começam a elevar-se, tendendo para uma inclinação uniforme de $+45^{\circ}$, indicando a contribuição do embasamento resistivo. Observa-se uma variação crescente na profundidade do embasamento de $60 \mathrm{~m}$ em SE-02 até $115 \mathrm{~m}$ em SE-05, com espessamento da Formação Aliança na direção nordeste.
As sondagens realizadas na área de exposição da Formação Sergi, SE-06 a SE-09, vêm representadas nas Figs. 5a e 5b. A Sondagem SE-09 foi representada separadamente, na Fig. 5b, por incluir perfil estratigráfico de poço. Verifica-se que todas essas curvas mostram uma camada superficial com resistividade e espessura variáveis, respectivamente 1 a $3,6 \mathrm{~m}$ e 500 a $4.700 \Omega \mathrm{m}$, que corresponde à cobertura do solo arenoso da região. Os arenitos (da Formação Sergi) subjacentes vêm representados nas curvas por camadas de elevada resistividade, entre 1.200 e $1.600 \Omega \mathrm{m}$. É visível nas curvas SE-07 e SE-09 a presença de camada condutora de pequena espessura, intercalada no arenito, identificada com base nos dados de perfuração como lentes argilosas no interior do Sergi. Essa camada condutora está ausente na curva SE-08. Uma terceira camada, de $340 \Omega \mathrm{m}$ de resistividade, na curva SE-06, deve possivelmente resultar do efeito de uma lente argilosa situada abaixo de $14 \mathrm{~m}$ de profundidade, apenas parcialmente manifestando o efeito da sua existência na curva. O espaçamento, nesse caso, foi limitado visando a evitar uma aproximação maior da zona silicificada associada à Falha da Umburana. O excelente condutor na base da formação, repre-

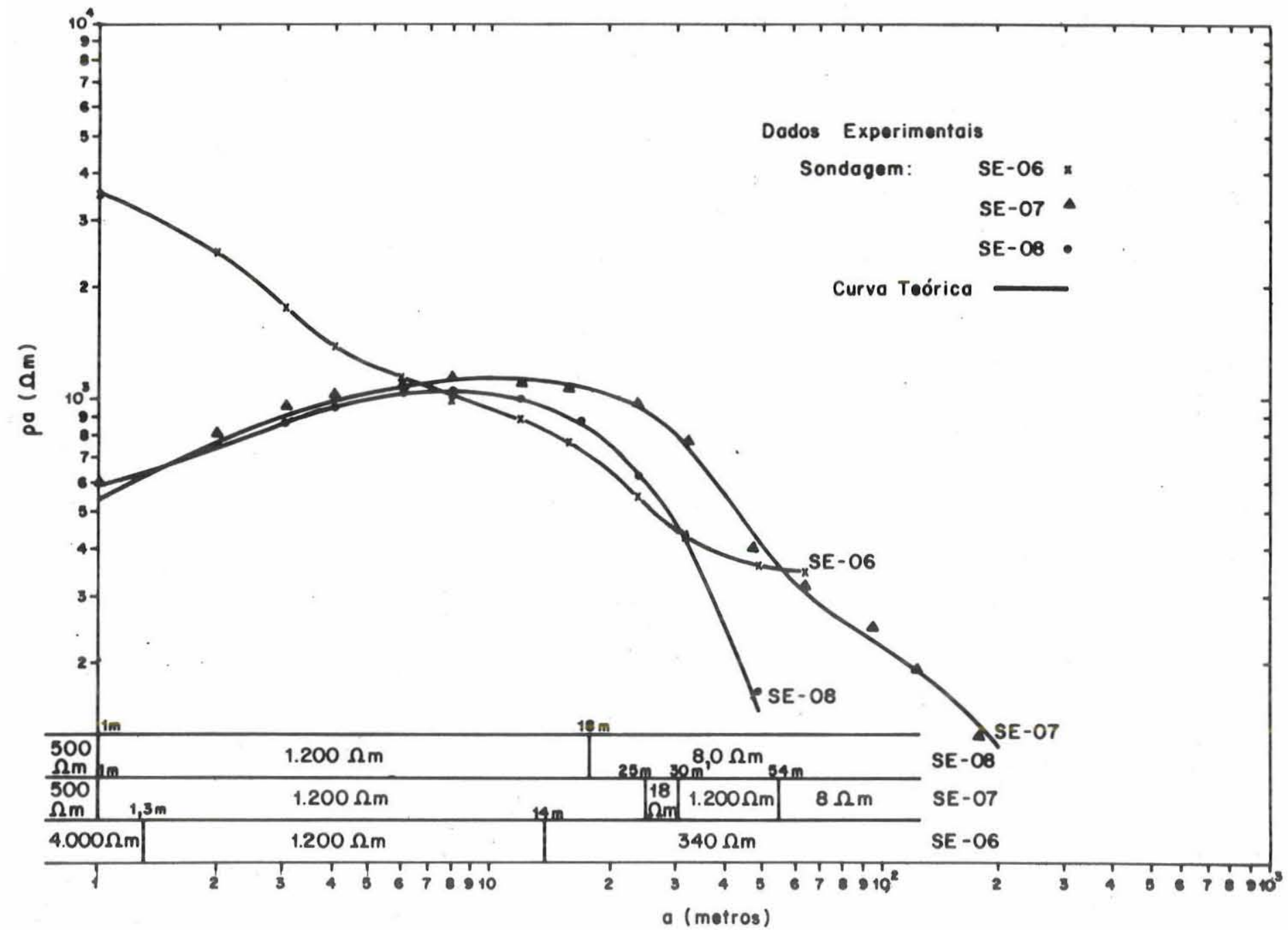

Figura 5a - Curvas de sondagens elétricas obtidas sobre a Formação Sergi 


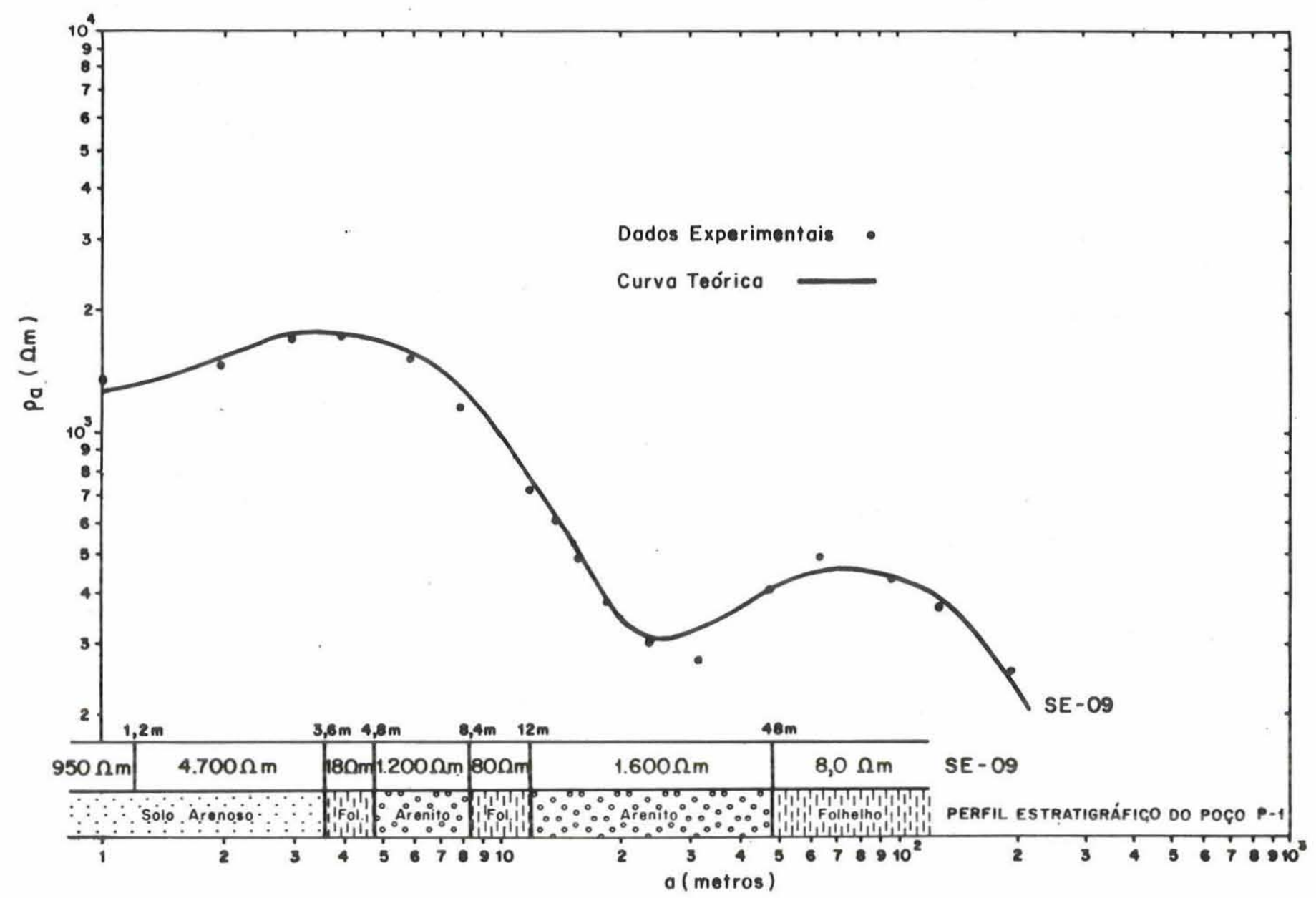

Figura $5 \mathrm{~b}$ - Sondagem elétrica sobre a Formação Sergi, acompanhada do perfil de poço executado no centro da sondagem

sentado pelos ramos terminiais fortemente descendentes das curvas SE-07, SE-08 e SE-09, representa os espessos folhelhos da Formação Aliança.

A curva SE-09 foi interpretada usando como dados iniciais as espessuras das camadas determinadas no perfil litológico do furo realizado no centro da expansão. Os valores de resistividade obtidos, após o ajustamento do modelo teórico à curva experimental, serviram para auxiliar na interpretação das curvas de sondagem obtidas nos demais centros sobre essa formação.

A concordância de valores, na Formação Sergi, entre algumas sondagens relativamente espaçadas, sugere que os arenitos possuem uma resistividade aproximadamente constante na área estudada. A interpretação das curvas de sondagem permitiu avaliar a espessura média do arenito Sergi entre 40 e $50 \mathrm{~m}$.

As sondagens executadas sobre a Formação Itaparica, SE-10 a SE-17, objetivaram determinar a continuidade do arenito Sergi no sentido do mergulho das formações e definir a posição de seu topo na zona de confinamento. Sobre a Formação Candeias, sondagens SE-18 a SE-20, o objetivo foi determinar as características estruturais e litológicas dessa formação e o confinamento lateral do arenito Sergi ao sul da Falha Serrote do Dió.

Na Fig. 6, são mostradas as sondagens obtidas ao norte da Falha Serrote do Dió, parte leste, dadas por
SE-10 a SE-13. Novamente, as curvas evidenciam a seqüência: a) camada superficial areno-argilosa de espessura variável e de elevada resistividade, com valores dados, respectivamente, por 2 a $6 \mathrm{~m}$ e 280 a $5.000 \Omega \mathrm{m}$; b) camada condutora eletricamente homogênea, com resistividade de 6 a $8 \Omega \mathrm{m}$, representando os folhelhos da Formação Itaparica; c) camada resistiva no ramo terminal da curva interpretada, com base na estratigrafia, como sendo o arenito Sergi.

A resistividade do folhelho da Formação Itaparica não pôde ser determinada precisamente com base apenas na interpretação das curvas de sondagem elétrica, em vista da sua espessura relativamente pequena e do elevado contraste de resistividade da mesma com as camadas adjacentes. A unicidade da interpretação pôde entretanto ser atingida, usando os valores de profundidade determinados com o método de refração sísmica. A partir dos resultados das sondagens elétricas nessa zona, foi possível estimar em torno de $8^{\circ}$, no sentido sudeste, o mergulho do topo do arenito Sergi.

Na Fig. 7, vêm representadas as sondagens realizadas sobre a Formação Itaparica, a oeste da Falha Pitombeira. Pode-se verificar, nas curvas dessa figura, que o padrão de distribuição da resistividade com a profundidade é muito semelhante àquéle das sondagens sobre essa formação, na parte leste, correspondendo à ocorrência do arenito Sergi recoberto por folhelhos, e 


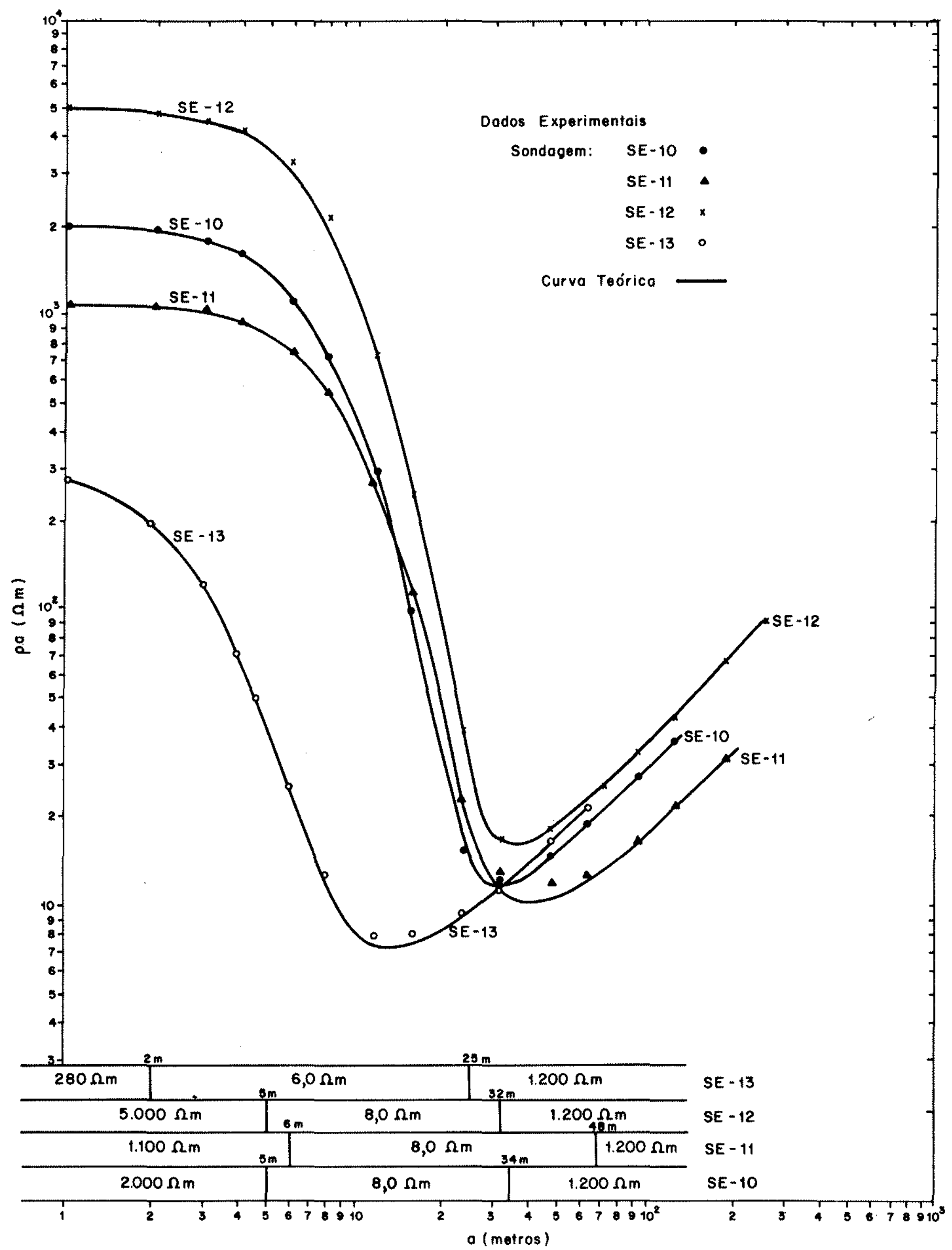

Figura 6 - Curvas de sondagens elétricas obtidas sobre a Formação ltaparica - parte leste 
estes por solo areno-argiloso. A curva SE-14 indica, sob a camada de solo, uma camada condutora com o mesmo valor de resistividade encontrado para os folhelhos tanto da Formação Aliança como da Formação Itapari$\mathrm{ca}$, isto é, valor entre 6 e $8 \Omega \mathrm{m}$. Nas sondagens SE-16 e SE-17, todavia, verifica-se que, abaixo da camada de solo, ocorre uma camada condutora com valor de resistividade de $18 \Omega \mathrm{m}$, valor um pouco mais elevado que aquele geralmente encontrado para os folhelhos na região. Esse aumento da resistividade deve resultar da presença de finas camadas ou lentes mais resistivas (siltitos ou arenitos), distribuídas nos folhelhos da Formação Itaparica. Os ramos terminais ascendentes das curvas são atribuídos à presença do arenito Sergi em profundidade.

A curva SE-15, representada também na Fig. 7, apresenta distorções características de descontinuidades laterais de resistividade. Para espaçamentos da ordem de $100 \mathrm{~m}$, a curva mostra um cúspide positivo, indicando que um dos eletrodos de corrente cruzou a descontinuidade lateral de resistividade. $O$ espaçamento correspondente a esse ponto de máximo define a-posição da interface em relação ao centro da sondagem. A linha pontilhada, indicada nos mapas das Figs. 2 e 3, indica o limite entre a Formação Sergi e a Formação Itaparica, conforme inferido pelo levantamento geofísico. E importante salientar que, com base no padrão textural das fotos aéreas, esse trecho da área foi mapeado inicialmente como arenito Sergi. Os dados geofísicos foram essenciais para a distinção posterior entre esse arenito e a Formação Itaparica.

As curvas de sondagens elétricas SE-18 a SE-20, realizadas ao sul da Falha Serrote do Dió, na área da Formação Candeias, vêm mostradas na Fig. 8. Por limitação instrumental, a máxima separação de eletrodos usada nessas sondagens foi insuficiente para avaliar a espessura da camada condutora, situada sob o solo arenoso da cobertura. A estimativa do valor mínimo da espessura dessa camada sugere um valor de, pelo menos, $340 \mathrm{~m}$ para a espessura dos folhelhos da Formação Candeias nessa zona.

Sísmica de refração O levantamento sísmico foi realizado ao longo de duas linhas transversais à estrutura geológica (Fig. 3), utilizando o sistema TRIO Mod. 5.352-ABEM, de 24 canais.

Os registros foram obtidos em arranjos lineares de 24 geofones com frequência natural de $4 \mathrm{~Hz}$, espaçados entre si de $11 \mathrm{~m}$, com pontos de tiro nos extremos da ex-

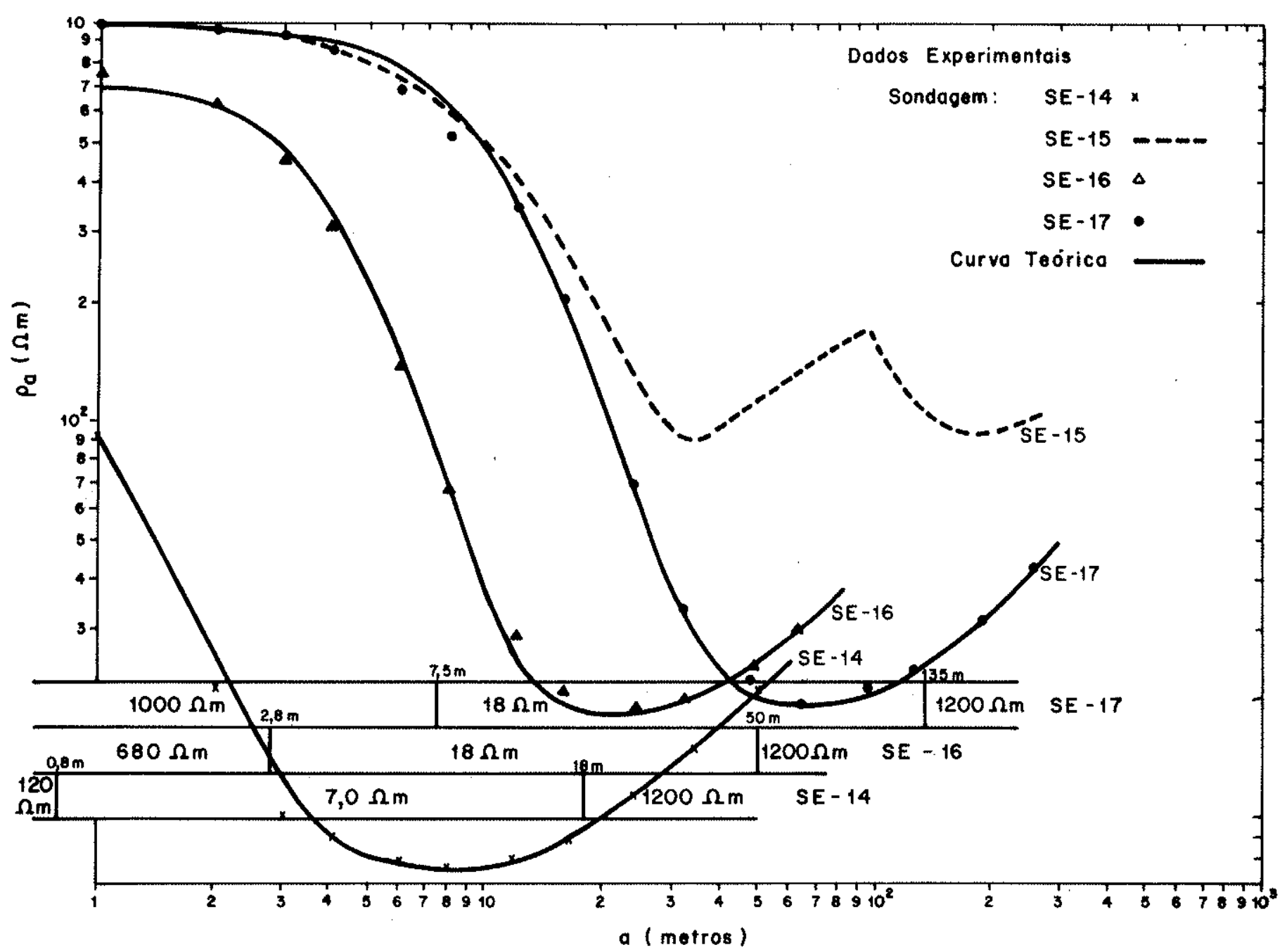

Figura 7 - Curvas de sondagens elétricas obtidas sobre a Formação Itaparica - parte oeste. 


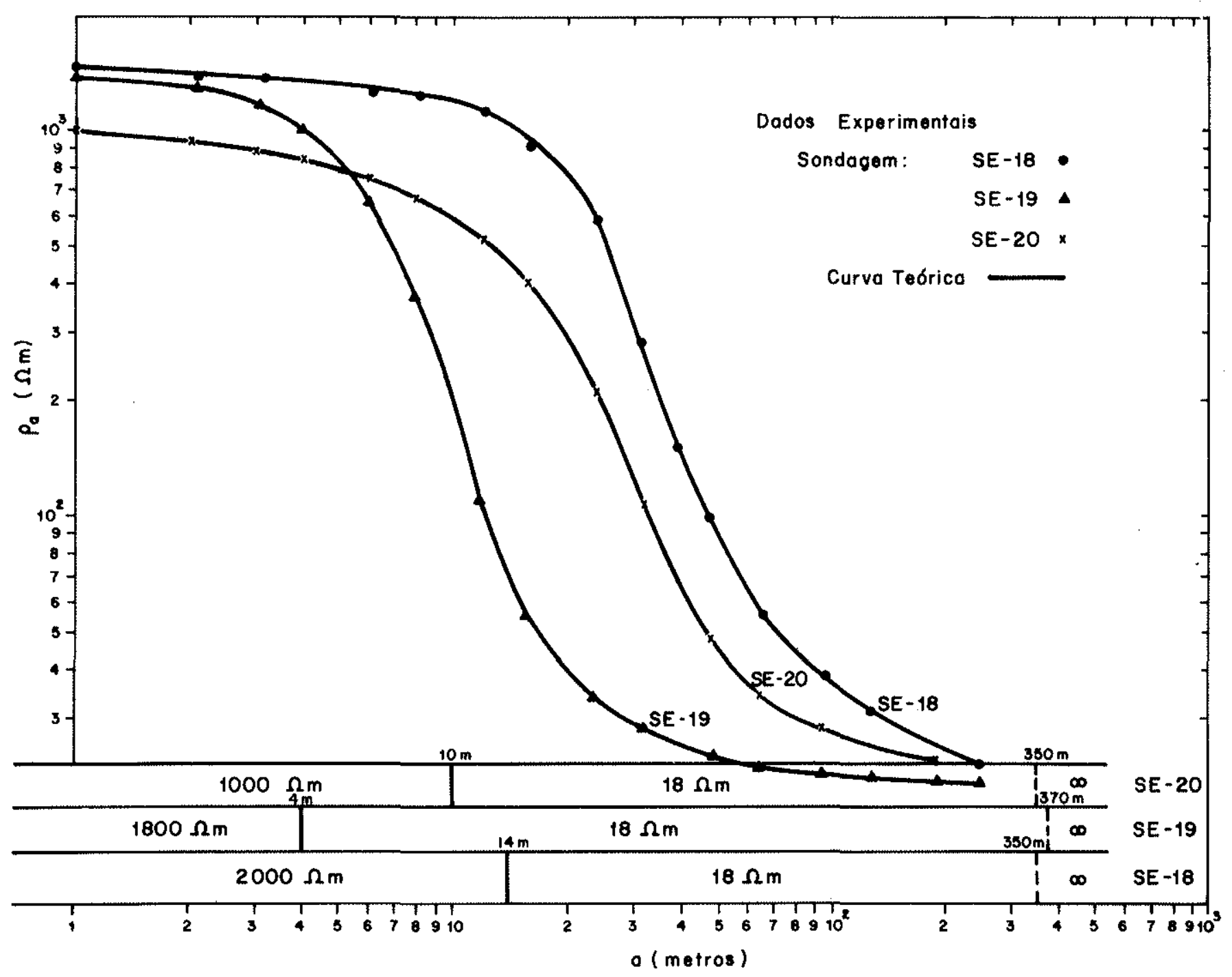

Figura 8-Curvas de sondagens elétricas obtidas sobre a Formação Candeias ao sul da Falha Serrote do Dió

pansão. Como fonte de energia, foram utilizadas explosões de dinamite a profundidades entre 2 e $4 \mathrm{~m}$, com cargas variando de 250 a $500 \mathrm{~g}$ de gelatina com $60 \%$ de potência: As expansões foram deslocadas ao longo de cada linha, mantendo continuidade no perfil. Dez tiros suplementares, de menor potência, foram realizados para determinação da camada de solo, com espaçamento entre os geofones variando de 1 a $3 \mathrm{~m}$. Todas as expansões foram niveladas a teodolito, de modo a obter um perfil topográfico preciso da linha levantada.

Os dados dos registros sísmicos foram inicialmente corrigidos para eliminar os efeitos da topografia, relativamente ao plano contendo os pontos de tiro e ortogonal ao plano vertical. Esse procedimento foi repetido para cada expansão. Essa correção é aproximadamente igual à relação $h_{\mathrm{g}} / V_{\mathrm{s}}$, onde $h_{\mathrm{g}}$ é a elevação do geofone em relação à superfície de referência e $V_{\mathrm{s}}$ a velocidade sísmica no solo (camada superior). Não foram necessárias as correções de intemperismo, porque a camada superficial é bastante homogênea, sendo por isso tratada como uma única camada.
$\mathrm{Na}$ interpretação dos perfis, foi utilizado o método do tempo recíproco, descrito por Hawkins (1961), complementado com o método da distância crítica e tempo de interseção (Heiland, 1940; Knox, 1967).

Perfil de refração $\mathrm{AB} \quad \mathrm{O}$ comprimento total desse perfil foi de $556 \mathrm{~m}$, envolvendo 2 expansões e 8 pontos de tiros. O gráfico tempo-distância, construído com base nos registros sísmicos, após correção de topografia, vem mostrado na Fig. 9. Nessa figura, estão mostradas também a superfície topográfica e a posição das interfaces refratoras mapeadas. Para determinação da velocidade na camada superficial, foram executadas pequenas expansðes diretas e reversas, com separação de geofones de $2 \mathrm{~m}$, em torno dos pontos extremos das expansões maiores do perfil.

A primeira camada, representada pelo solo areno-argiloso, possui baixa velocidade, mas aproximadamente constante, de cerca de $400 \mathrm{~m} / \mathrm{s}$, conforme determinado com os dados das expansões com $2 \mathrm{~m}$ de separação entre os geofones. A espessura irregular dessa camada é 

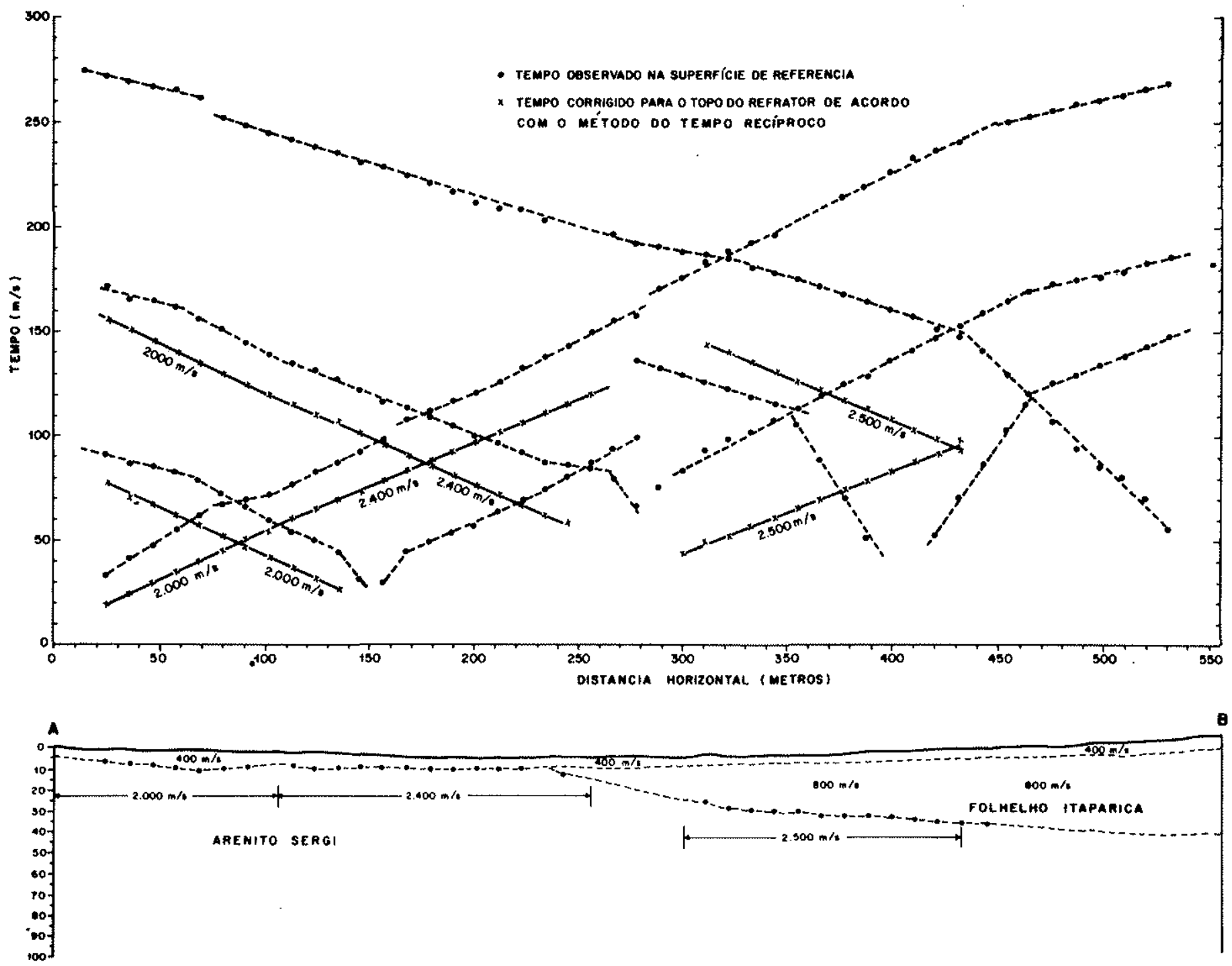

Figura 9 - Perfil de sísmica de refração $\mathrm{AB}$, com interpretação da estrutura geológica

responsável pela dispersão verificada no gráfico tempo-distância, no perfil $\mathrm{AB}$, em torno das retas de velocidade aparente dos refratores.

Na metade do perfil, à esquerda, na Fig. 9, identifica-se apenas uma interface refratora, de topografia ligeiramente irregular, que separa a camada areno-argilosa do arenito Sergi. Esse arenito apresenta velocidade sísmica média, que cresce lateralmente de $2.000 \mathrm{~m} / \mathrm{s}$ a $2.400 \mathrm{~m} / \mathrm{s}$ no sentido do mergulho dessa formação. $\mathrm{O}$ fato de a velocidade ser mais baixa em um trecho no extremo à esquerda do perfil é atribuído a uma diminuição da coesão na formação, possivelmente relacionada com a existência de sistemas de fraturas associados com uma proximidade maior da falha adjacente a esse extremo do perfil AB. Essa interpretação é consistente com os dados do resto do perfil, que mostra uma uniformidade do comportamento elástico do arenito. As lentes argilosas no interior do arenito, indicadas nas sondagens elétricas e confirmadas pela perfuração, não se manifestam nos gráficos tempo-distância como superfícies de descontinuidade de velocidade sísmica. Esse fato in - dica que a concentração de argila em certas seções da formação afetam fortemente o seu comportamento elétrico, mas não de modo apreciável o comportamento elástico do meio.

Na metade do perfil, à direita, ainda na Fig. 9, registra-se um refrator de velocidade $800 \mathrm{~m} / \mathrm{s}$, logo abaixo da camada do solo e acima do arenito Sergi, interpretado como os folhelhos da Formação Itaparica. O baixo valor de velocidade verificado nessa camada parece indicar um certo grau de alteração das rochas constituintes, uma vez que normalmente seria de esperar velocidade mais alta que esse valor (Dobrin, 1960, p. 22). O refrator subjacente, interpretado como sendo o arenito Sergi, ocorre inclinado de $6^{\circ}$, com velocidade sísmica de $2.500 \mathrm{~m} / \mathrm{s}$. O mergulho obtido para essa interface concorda, em boa aproximação, com o valor de $8^{\circ}$ determinado por eletrorresistividade.

Perfil de refração $C D$ Esse perfil, com $536 \mathrm{~m}$ de extensão, envolveu também 2 expansðes e 8 pontos de tiros. A camada de solo, de baixa velocidade, foi determi- 
O limite lateral do corpo arenítico ao longo da Falha Serrote do Dió está representado por folhelhos da Formação Candeias. Embora a profundidade da base dessa formação não tenha sido precisada com os dados elétricos, foi possivel estimar que a mesma ocorre a profundidades superiores a $350 \mathrm{~m}$, isto é, bem maiores do que a parte mais profunda do arenito. Dependendo do grau de fraturamento do folhelho, esse contorno poderá funcionar como barreira lateral impermeável ou semi-permeável.

O trecho delimitado por um retângulo na Fig. 3 , caracterizado pela uniformidade no comportamento elétrico e sísmico da Formação Sergi e por uma configuração estrutural relativamente mais simples, foi seleciona- do como o sítio mais apropriado para a experimentação da injeção artificial de água através de poços, a ser realizada.

Agradecimentos Os autores agradecem aos Profs. Ronald D. Barker e Shiguemi Fujimori por valiosas sugestðes, e à Prof. Yeda de A. Ferreira pelo seu apoio e incansável estímulo. Esta pesquisa foi financiada pela Superintendência do Desenvolvimento do Nordeste (SUDENE), pelo Conselho Nacional de Desenvolvimento Científico e Tecnológico (CNPq), e pela Financiadora de Estudos e Projetos (FINEP), e realizada sob a responsabilidade do Programa de Pesquisa e Pós-Graduação em Geofísica da Universidade Federal da Bahia.

\section{BIBLIOGRAFIA}

BARROS, J.G. e FEI'TOSA, E.C. - 1967 - Estudo Geofísico por Prospeç̧ão Elétrica. Feira de Santana-BA. SUDENE, Série Hidrogeologia, n: 14, $29 \mathrm{pp}$ CARPENTER, E.W. e HABBERJAM, G.M. - 1956 - A tripotential method of resistivity prospecting. Geophysics, 21(2): 455-469.

DOBRIN, M.B. - 1960 - Introduction of Geophysical Prospecting. McGrawHill, New York.

HABBER JAM, G.M. e WATKINS, G.E. - 1967 - The reduction of lateral effects in resistivity probing. Geophys. Prosp. 15(2): 221-235.

HAWKINS, L.V. - 1961 - The reciprocal method of routine shallow seismic refraction investigation. Geophysics 26(6): 806-819.

HEILAND, C.A. - 1940 - Geophysical Exploration, Prentice Hall, New York.

HUMPHREY, H. e ALLARD, G. - 1969 - Geologia do Domo de Itabaiana, Bol. Tec. Petrobrás n: 83, 157 pp.

KNOX, W.A. - 1967 - Multilayer near-surface refraction computations. In: Seismic Refraction Prospecting. A.W. Musgrave, Ed. Soc. Exp. Geophysicists. Tulsa, Oklahoma.

LIMA, O.A.L. - 1979 - Estudo da Utilizaçào de Reservatórios Subterrâneos Naturais para Armazenamento de Ägua numa Área Experimental na Regiào
Semi-árida do Nordeste Brasileiro. Tese de Doutorado, PPPG/UFBa, Salvador, $158 \mathrm{pp}$.

LIMA, O.A.L. e DIAS, C.A. - 1979 - Estudo das Propriedades Hidrodinâmicas da Formação Sergi Numa Area Experimental na Região de Cocorobó-BA. Revista Brasileira de Geociências 9(2): 140-150.

MOONEY, H.M., ORELLANA, E., PICKETT, H, e TORNHEIN, L. - 1966 - A resistivity computing procedures for layered earth models. Geophysics 31(1): $192-203$

RIJO, L.,. PELTON, W.H., FEITOSA, E.C. e WARD, S.H. - 1977 - Interpretation of apparent resistivity data from Apodi Valley, Rio Grande do Norte, Brasil, Geophysics 42(4): 811-822.

SAMPA1O, E.E.S., 1978 - Perfilagem Eletromagnetica de Falhas e Diques Verticais Empregando Campos de Onda Plana. Tese de Doutorado, PPPG/UFBa, Salvador, $152 \mathrm{pp}$.

VIANA, C.I., GAMA Jr., E.G., SIMÕES, 1.A., MOURA, J.A., FONSECA J.R. e ALVES, R.J. - 1971 - Revisão Estratigráfica da Bacia Recôncavo/rucano. Bol. Tec. Petrobrás 14(3/4): 157-192.

WARD, S.H., O'DONNEL, J., RIVERA, R. e WARE, G.H. - 1966 - AFMAG Applications and Limitations. Geophysics 31(3): 576-605. 